Portland State University

PDXScholar

9-1-1969

\title{
An experimental study of the effects of personal proximity upon selected aspects of conversational content
}

Ronna S. Loewen

Portland State University

Follow this and additional works at: https://pdxscholar.library.pdx.edu/open_access_etds Let us know how access to this document benefits you.

\section{Recommended Citation}

Loewen, Ronna S., "An experimental study of the effects of personal proximity upon selected aspects of conversational content" (1969). Dissertations and Theses. Paper 631.

https://doi.org/10.15760/etd.631

This Thesis is brought to you for free and open access. It has been accepted for inclusion in Dissertations and Theses by an authorized administrator of PDXScholar. Please contact us if we can make this document more accessible: pdxscholar@pdx.edu. 
AN ABSTRACT OF THE THESIS OF Ronna S. Loewen for the Master of Science in Speech presented September 4, 1969.

Title: An Experimental Study of the Effects of Personal Proximity Upon Selected Aspects of Conversational Content

\section{APPROVED BY MEMBERS OF THE THESIS COMMITTEE:}

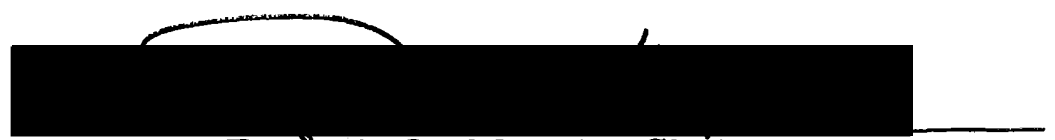

Patrick O. Marsh, Chairman

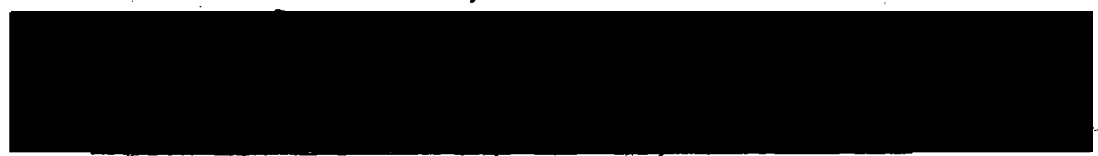

Larry/Steward
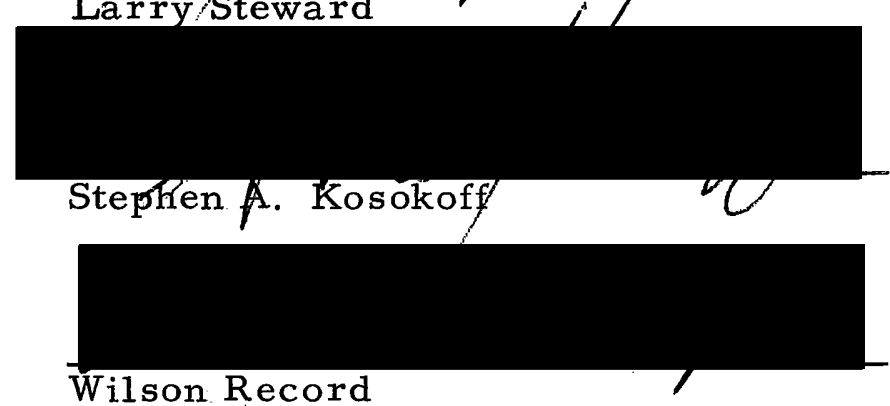

Proxemics is an area of study devoted to the interrelated theories of man's use of space as a special elaboration of culture.

Edward T. Hall, an anthropologist, has begun to draw these theories together in his work dealing with proxemics.

It is the purpose of this study to determine whether certain dimensions of interpersonal conversations vary with the distance 
between the conversants. Three distances were used as experimental variables. Intimate distance was set at nine inches, personal dis tance at three feet, nine inches, and social distance at eight feet. A total of fifty-four subjects was used with nine pairs situated in each of the three distances. Conversations between dyads were tape recorded and subjected to content analysis.

Eight categories were established to cover certain dimensions hypothesized to exist in interpersonal communication. Data from the content analysis were subjected to statistical interpretation with six out of eight hypotheses revealing significant differences. The hypotheses and principal findings are as follows:

Hypothesis 1. Frequency of references to the speaking situation will vary with the distance variables.

A significant difference was found. Intimate distance conversants referred least to the situation and social distance conversants referred most often to the situation. Personal distance subjects' references were closely allied with the expected frequency. Hypothesis 2. Time orientation as revealed by verb tense will vary with the distance variables.

This hypothesis also revealed a significant difference. All subjects chose to use the present tense most often. Intimate and personal distance conversants preferred the future tense second and the past tense last. Subjects in social distance chose the past tense 
second and the future tense least.

Hypothesis 3. Frequency of references to self and others will vary with the distance variables.

No significant difference was found.

Hypothesis 4. Total pause time will vary with the distance variable.

Total pause time did not differ.

Hypothesis 5. Signs of tension (such as laughing, coughing, sighing) will vary with the distance variables.

A significant difference existed in this category. Intimate distance conversants revealed the most tension releases, social distance the second most, and personal distance the least.

Hypothesis 6. Types of statements will vary with the distance variables ("asking" and "giving" information).

A significant difference was found. Subjects placed at intimate distance gave and asked for the most information, Subjects in social distance ranked second in both "giving" and "asking" for information and personal distance subjects ranked third in both categories. Hypothesis 7. Frequency in changing the topic of conversation will vary with the distance variables.

Different distances did affect the changes made in the topic of conversation with intimate distance deviating the most from the expected frequency and personal the least. Hypothesis 8 . Frequency of short vocal reinforcements (such as 
"oh," "really," "huh") vary with the distance variables.

A significant difference was found. Intimate and social distance conversants used the most reinforcements and personal the least.

Some general conclusions can be made about the selected aspects of conversations within the three distances. Intimate distance might be observed to be most uncomfortable for subjects. More tension releases, changes in the topic of conversation, and vocal reinforcements existed than in the other distance conversations. The situation was seldom mentioned perhaps indicating avoidance. The most information passed between these subjects suggesting a rapid speaking rate and nervousness.

Social distance also appeared to be less than comfortable for subjects by ranking second in several of the categories. Personal distance had the least vocal reinforcements, topic changes, references to the speaking situation and amount of "giving" and "asking" of information. It is concluded that personal distance is the most appropriate distance for casual conversation between two strangers placed in a situation encouraging verbal interaction. 
AN EXPERIMENTAL STUDY OF THE EFFECTS OF PERSONAL PROXIMITY UPON SELECTED ASPECTS OF CONVERSATIONAL CONTENT

by

RONNA S. LOEWEN

A thesis submitted in partial fulfillment of the requirements for the degree of

\section{MASTER OF SCIENCE \\ in \\ SPEECH}

Portland State University

1969 
TO THE OFFICE OF GRADUATE STUDIES:

The members of the Committee approve the thesis of

Ronna S. Loewen presented September 4, 1969.

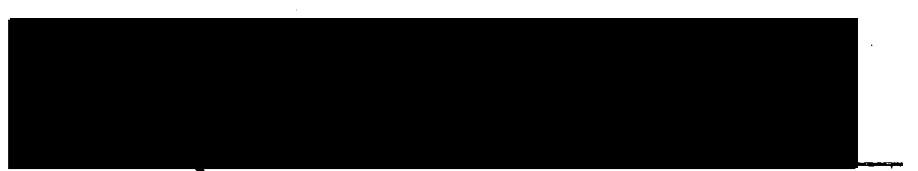

Patrick O. Marsh, Chairman

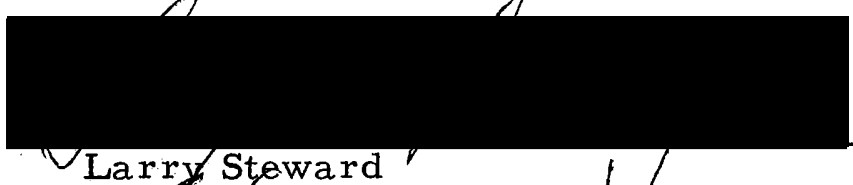

Steward

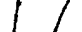

Stepheh A. /Kosokoff

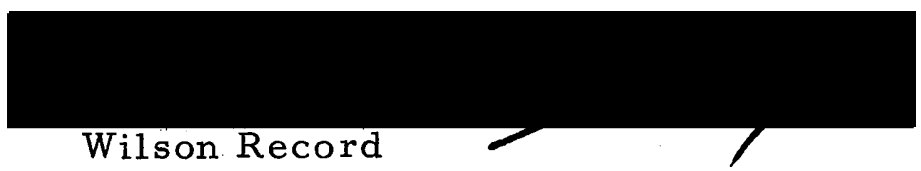

APPROVED:

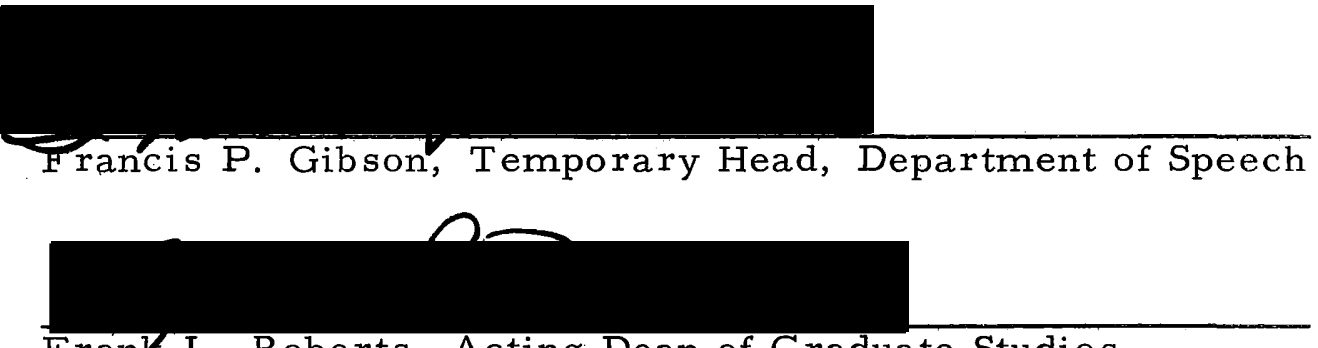

Frank L. Roberts, Acting Dean of Graduate Studies

September 8, 1969 


\section{ACKNOW LEDGMENTS}

It seems only appropriate that this thesis begin with an acknowledgment to one person who has so willingly given of his time, assistance, and enthusiasm, my chairman, Dr. Patrick Marsh. 
TABLE OF CONTENTS

PAGE

ACKNOW LEDGMENTS . . . . . . . . . . . . . . iii

LIST OF TABLES .................. . . . . . vi

CHAPTER

I INTRODUCTION. .............. 1

Background .............. . . 1

Purpose of the Study. . . . . . . . 2

Limitations . . . . . . . . . 4

II REVIEW OF THE LITERATURE . . . . . . 6

A General Summary Concerning the Study of Proxemics........... 6

Studies Directly Related to Proxemics . . 16

III DESIGN OF THE STUDY ........... 19

Population .............. . . 19

Experimental Variables ........ 20

Content Analysis . . . . . . . . . 21

Reference to Speaking Situation

Time Orientation

References to Self and Others

Pause Time

Tension Releases

Kinds of Statements

Changing the Subject

Vocal Reinforcement 
CHAPTER

PAGE

Hypotheses of the Study . . . . . . .

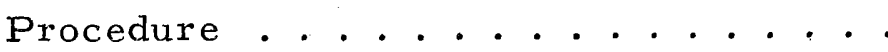

IV FINDINGS ................

V SUMMARY AND CONCLUSIONS . . . . . .

Summary of the Findings . . . . . .

Conclusions. . . . . . . . . . . .

Intimate Distance

Personal Distance

Social Distance

Suggestions for Further Research.... .

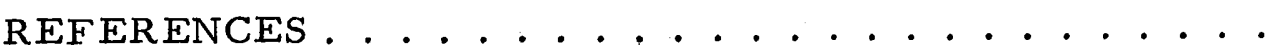

\section{APPENDIX}

A Diagram of Kinzel's Theory of the Violent and Nonviolent Man . . . . . . . . . . .

B Visual Field of a Person at Intimate, Personal and Social Distance . . . . . . . . . .

C Invitation Asking Student Participation . . . .

D Instructions Read to Subjects before Their Conversation was Taped . . . . . . . . . 


\section{LIST OF TABLES}

TABI_E

PAGE

I Visual Angles of Hall's Distance.........

II Chi-Square Test for the Variable "References

to the Speaking Situation" .........

III Time Orientation Revealed by Verb Tense

(Observed Frequency) . . . . . . . .

IV Time Orientation Revealed by Verb Tense

(Expected F requency) . . . . . . . . .

V Chi-Square Test for Time Orientation Revealed

by Verb Tense ...............

VI Hierarchy of Verb-Tense Preferences According

to Distance Group . . . . . . . . . .

VII References to Self and Others (Observed

Frequency) . . . . . . . . . . .

VIII References to Self and Others (Expected

Frequency)................

IX Chi-Square Test for References to Self and Others

X Summary of $\underline{t}$-Test Results for Pause Time ...

XI Chi-Square Test for Signs of Tension . . . . . 
XII "Asking" and "Giving" Information (Observed Frequency) . . . . . . . . . . . .

XIII "Asking" and "Giving" Information (Expected Frequency) ...............

XIV Chi-Square Test for "Asking" and "Giving" Information .............

XV "Giving" Information--Opinion, Factual Information, Suggestion (Observed Frequency). . . .

XVI "Giving" Information--Opinion, Factual Information, Suggestion (Expected Frequency). . . .

XVII Chi-Square Test for "Giving" Information--

Opinion, Factual Information, Suggestion . .

XVIII Chi-Square Test for Change in the Topic of Conversation ... . . . . . . . . .

XIX Chi-Square Test for Frequency of Vocal

Reinforcements ............ 


\section{CHAPTER I}

\section{INTRODUCTION}

\section{BACKGROUND}

In the study of communication, man's non-verbal behavior has been observed to possess significant meaning. Through socialization people learn that a gesture or vocal inflection serves to augment the spoken word. Culture determines non-verbal meanings within a society. Edward T. Hall states that culture itself serves as a means of communication. ${ }^{1}$ Culturally determined behaviors associated with verbal communication affect that communication. One such behavior is what Hall labels proxemic behavior.

Proxemics is a word Hall coined in reference to "inter related theories of man's use of space as a specialized elaboration of culture. $"{ }^{2}$ In The Hidden Dimension, Hall establishes theories about spatial relationships. Distances people establish between themselves and their fellow humans communicate meaning. Meaning attached to

${ }^{1}$ Edward T. Hall, The Silent Language (Garden City: Doubleday and Company, 1959). The entire book is devoted to establishing this concept.

${ }^{2}$ Edward T. Hall, The Hidden Dimension (Garden City: Doubleday and Company, 1966), p. 1 . 
certain spatial behaviors is culturally determined. For instance, in the United States people assume that when one person places himself close to another person, he is doing so because he knows that person well. Americans are not likely to stand, voluntarily, as close as twelve inches from a stranger. Arabs however feel no compunction whatsoever in standing this close to another person. ${ }^{3}$ They do not feel an individual's personal world can be physically intruded. Germans see their own egos extended out into space. They feel everyone should have his own private area with a definite boundary. A door is meant to enclose this space. Doors are constructed sturdily, shut tightly, and are meant to be closed in Germany. Americans are likely to consider this practice overly private and even suspicious. Therefore, doors in the United States do not hold the same meaning as they do in Germany. ${ }^{4}$ Physical distance and partitions of space, then, serve to establish a setting for communication. It would be expected that spatial relationships, a variable in the communication setting, would affect communication between people.

\section{PURPOSE OF THE STUDY}

This thesis was inspired by Hall's work. He created a framework which indicated a need for controlled empirical study. The

$$
{ }^{3} \text { Ibid., p. } 149 . \quad \quad 4 \text { Ibid., p. } 128
$$

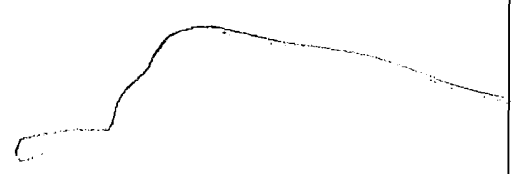


purpose of this study is to determine whether certain dimensions of interpersonal conversations vary with the distance between the conversants. This study will isolate certain communication variables thought to be related to proxemics and will examine them with regard to three distances described by Hall: intimate, personal, and social. $^{5}$

It is hypothesized that conversation between strangers within the intimate space boundary will be characterized by signs of tension, references to the situation, cautious statement of personal feelings, and a great deal of feedback. In this study, feedback refers to a verbal response stimulated by an input of communication. These characteristics seem predictable because of the meaning Americans attach to close physical distance. This type of spatial distance is un natural in our culture for strangers. Manifestations of this atypical situation are expected to be revealed in verbal behavior.

Personal distance does not invade this intimate, private sphere. Therefore, it is hypothesized that there will be fewer signs of tension and references to the situation. Types of statements and the amount of feedback are also expected to differ. Usually people do not place themselves close, three feet apart, to strangers unless they are desirous of becoming acquainted. The experimental situation,

${ }^{5}$ An explanation of these categories established by Hall will appear later within the thesis. 
however, will place them in this circumstance. It may be discovered that this distance, rather than social, will be the most natural since the subjects are acquainting themselves with each other.

Social distance is expected to produce behavior closest to that which people would exhibit normally with strangers. It is believed that the subjects will feel most comfortable in this situation. It is hypothesized that verbal behavior will include more freedom in types of statements made, less pressure for feedback, fewer examples of tension, and little reference to the situation.

This explanation of specific expectations indicates some of the areas that are to be considered in the verbal content. The central inquiry is to uncover whether differences do occur in verbal conversation when spatial distances between people are altered.

\section{LIMITATIONS}

All studies conducted within a laboratory are limited in their observations. This study is not excluded from this limitation. The subjects are placed in an unnatural setting, a laboratory. A tape recorder, of which the subjects are aware, serves as a silent member in the communicative situation. Precautions that are taken to keep the subjects at a certain distance attract attention to the distance factor itself. Seating the subjects also cancels out possible variations in vertical distance that might occur if they were standing. 
Asking the participants to converse, also places certain demands on them, and they are likely to be overly conscious of what is being said. Yet the laboratory serves the function of controlling variables to a degree which is not possible in field research. Hall acknowledges the difficulty of research techniques:

No single research technique is sufficient in scope to investigate a complex multidimensional subject like proxemics. The technique employed is a function of the particular facet of proxemics under examination at a given moment. 6

The study is also limited in the population from which the subjects were chosen. They were Caucasian American college students of a university in Portland, Oregon. Since culture alters proxemic behavior, all foreign students and those of American subcultures (Negro, Mexican, Indian, Puerto Rican, and Oriental Americans) were not included in the sampling. It was felt cultural differences were a variable requiring control. College students from one university in a particular locale were chosen because of convenience. The size of the sample and the college classes from which it was drawn were also limited for the same reason. Time has been a limiting factor in this study. Conclusions from this study will be drawn with these limitations in mind.

${ }^{6}$ Hall, The Hidden Dimension, p. 171. 


\section{CHAPTER II}

\section{REVIEW OF THE LITERATURE}

Proxemics is a relatively new field of study. Therefore a meaningful review of the literature necessitates locating proxemics within a larger framework. This perspective will offer a better understanding of the hypotheses being studied as well as indicating where other studies related to the field can be found. The chapter includes the following: (1) a general summary of literature concerning proxemics, and (2) experimental studies directly related to proxemics.

\section{A GENERAL SUMMARY CONCERNING THE STUDY OF PROXEMICS}

Proxemics, "theories of man's use of space as a specialized elaboration of culture, "1 may be viewed as a specialized area of ethnology. Ethnology, a branch of anthropology, studies the life ways of living people. ${ }^{2}$ Material relevant to man's spatial concepts

${ }^{1}$ Hall, The Hidden Dimension, p. 1.

${ }^{2}$ Ralph L. Beals and Harry Hoijer, An Introduction to Anthropology (New York: The Macmillan Company, 1965), p. 2. 
can also be found in architecture, experimental psychology, biology, sociology, urban planning, and psychiatry. ${ }^{3}$ The most systematic study has been conducted by Hall, the anthropologist, whose primary concerns are the spatial behavior of humans and how it differs from culture to culture. Culture can be traced back to biological activities. Man's elaboration of space patterns is especially illustrative of this concept. 4 Therefore in discussing the origin of spatial behavior, as well as the study of proxemics, it is important to consider territoriality of animals.

Territoriality, a basic concept in animal behavior, is usually defined as "behavior by which an organism characterically lays claim to an area and defends it against members of its own species. ${ }^{5}$ It can be considered a basic behavioral system of living 7 . organisms including man. "Territorology" was the word coined by Hediger, an important theorist in the field, to indicate the study of space-structure behavior in animals. 6

${ }^{3}$ Edward T. Hall, "Proxemics--A Study of Man's Spatial Relationships," in Man's Image in Medicine and Anthropology, ed. by I. Gladston (New York: International Universities Press, 1963), p. 423.

4 Ibid. , p. 424.

${ }^{5}$ Hall, The Hidden Dimension, p. 7.

${ }^{6}$ Hall, "Proxemics--A Study of Man's Spatial Relationships," p. 422 . 
The systematic study of territoriality began in 1920 , with the publication of Howard's, Territory in Bird Life. ${ }^{7}$ His work was followed by Hediger, an animal psychologist, who developed theories regarding the effect of territoriality on population density and survival of the species. He developed the concept of flight distance-how closely an animal could be approached before it would flee. ${ }^{8}$ His explanation of social and personal distance was a major contribution in the explanation of animal behavior. Social distance is the perimeter beyond which an animal will not separate himself from the group, and personal distance refers to the normal spacing of animals between themselves. 9 Hediger also made the distinction between contact and non-contact species. Contact behavior is exhibited by touching in both public and private, while non-contact groups do not usually touch in public. ${ }^{10}$ Carpenter studied territoriality in monkeys and birds and began to synthesize work in the field. Von Uexell took a more psychological approach and explained the perceptual world of animals as a space bubble which he called the "Umvelt." Hall's book, The Hidden Dimension, gives a good summary of work done on animal territoriality.

${ }^{7}$ Ibid. , p. $424 . \quad \quad 8$ Ibid. $\quad 9$ Ibid., p. 422.

${ }^{10}$ Edward T. Hall, "Silent Assumptions in Social Communication, " in Disorders in Communication, XLII ed, by Rioch and Weinstein (Baltimore: Williams and Wilkins Company, 1964), p. 45. 
Man also exhibits territorial behavior but to a more sophisticated degree. He moves in a highly patterned spatial system which varies from culture to culture. ${ }^{11}$ His proxemic behavior has developed to an almost unbelievable extent but has remained largely unrecognized. 12 Proxemics differs from territoriality because of its cultural basis and complexity. Hall develops three aspects of proxemics--fixed feature, semi-fixed feature and dynamic feature. ${ }^{13}$ The fixed feature of proxemics includes such manifestations as architectural design in buildings and roads. The semi-fixed feature refers to how man controls his interaction with others by the use of objects, such as patterns of furniture arrangement. The dynamic feature indicates "how man influences his communication with others by varying the spatial features of the situation. "14 An example would be where a person chose to stand or sit in relation to others. Proxemics appears to Hall to be an out-of-awareness behavior. ${ }^{15}$ People do not consciously consider their spatial behavior patterns,

${ }^{11}$ Hall, "Proxemics--A Study of Man's Spatial Relationships," p. 426 .

${ }^{12}$ Hall, The Silent Language, p. 147.

${ }^{13}$ Hall, "Proxemics--A Study of Man's Spatial Relationships," p. 429.

\section{Ibid.}

${ }^{15}$ Hall, "Silent Assumptions in Social Communication, " p. 54. 
yet each culture possesses them.

When Hall began his writing, the concept of proxemics or territoriality had been defined in operational, a priori ways. As he researched the field, empirical descriptions emerged to help refine some definitions utilized. Therefore, the definition of proxemics and other related terms have become synthetic in nature. In extensive interviews, Hall discovered that subjects couldn't explain how they discriminated between spatial distances, but still possessed definite feelings in regard to these distances. ${ }^{16}$ Subjects reported reactions to situations where distance was perceived to communicate meaning. Hall conducted extensive observation in many cultures and discovered noticeable differences in people's spatial behavior and reactions to the spatial behavior of others. Hall concluded that the study of space is a bio-basic, culturally modified system of behavior. 17

Although man's spatial behavior differs from other animals, he does share the problem of sensing proximity of other humans. Culture gives meaning to a specific distance, but the senses are the discriminators of that distance. Hall, using Hediger's term, states Americans are similar to a non-contact species. They do not like

16 Ibid. , p. 49.

17 Hall, "Proxemics--A Study of Man's Spatial Relationships," p. 441 . 
touching and consider contact cultures "pushy."18. Tactile, kinesthetic, visual, olfactory, and aural sensations allow man to locate himself in relation to others ${ }^{19}$ (See Hall's tabular description of areas covered at varying distances and visual angles, Table I, p. 12). Americans rely heavily on tactile-kinesthetic and visual senses whereas Eastern Mediterranean urban Arab cultures utilize olfactory and tactile cues. ${ }^{20}$ The sensitivity of the receptors would seem to be influenced by culturally determined space behaviors. So contact cultures might depend more on thermal, tactile, olfactory sensations more than non-contact cultures which would probably depend heavily on visual and aural sense data.

Hall labeled four space territories for American culture-intimate, personal, social and public space. The distances were determined through observation and interview. The subjects were

${ }^{18}$ Hall, "Silent Assumptions in Social Communication," p. 45.

${ }^{19}$ Hall develops a notation system for explaining man's method of determining spatial relationships. He states that proxemic behavior can be seen as a function of eight different dimensions and their appropriate scales. The dimensions include: (1) postural-sex identifiers, (2) sociofugal-sociopetal orientation, (3) kinesthetic factors, (4) touch code, (5) retinal combinations, (6) thermal code, (7) olfaction code, (8) voice loudness scale. Edward T. Hall, "A System of Notation of Proxemic Behavior," American Anthropology, 65, (October, 1963), pp. 1003-26.

${ }^{20}$ Hall, "Silent Assumptions in Social Communication," p. 45. 
TABLE I

VISUAL ANGLES OF HALL'S DISTANCES ${ }^{21}$

\begin{tabular}{|c|c|c|c|c|c|}
\hline \multirow{2}{*}{\multicolumn{2}{|c|}{ Distances }} & \multicolumn{4}{|c|}{ Visual Angles } \\
\hline & & $1^{\circ} *$ & $15^{\circ} \times 3^{\circ} * *$ & $60^{\circ}$ sweep $* * * *$ & $180^{\circ}$ \\
\hline \multicolumn{6}{|c|}{ Intimate } \\
\hline & $6^{\prime 1}$ & $0.1 " 1$ & $\begin{array}{l}2.5^{\prime \prime} \times 0.3^{\prime \prime} \\
\text { eye, mouth }\end{array}$ & $6 "$ the face & $\begin{array}{l}\text { Head and } \\
\text { shoulders }\end{array}$ \\
\hline & $18^{\prime \prime}$ & $\begin{array}{l}0.3^{\prime \prime} \text { central } \\
\text { iris }\end{array}$ & $\begin{array}{l}3.75^{\prime \prime} \times 1^{\prime \prime} \\
\text { upper or } \\
\text { lower face }\end{array}$ & $18^{\prime \prime}$ head & $\begin{array}{l}\text { Upper body } \\
\text { and arms }\end{array}$ \\
\hline \multicolumn{6}{|c|}{$\begin{array}{l}\text { Casual- } \\
\text { personal }\end{array}$} \\
\hline close & $30^{\prime \prime}$ & $\begin{array}{l}0.5^{\prime \prime} \text { tip of } \\
\text { nose }\end{array}$ & $\begin{array}{l}6.25^{\prime \prime} \times 1.5^{\prime \prime} \\
\text { upper or } \\
\text { lower face }\end{array}$ & $\begin{array}{l}30 " \text { head, } \\
\text { shoulders }\end{array}$ & Whole figure \\
\hline far & $48^{\prime \prime}$ & $0.8^{\prime \prime}$ one eye & $\begin{array}{l}10^{\prime \prime} \times 2.5^{\prime \prime} \\
\text { upper or } \\
\text { lower face }\end{array}$ & $48^{\prime \prime}$ waist up & \\
\hline \multicolumn{6}{|c|}{$\begin{array}{l}\text { Social } \\
\text { consultative }\end{array}$} \\
\hline close & $7^{\prime}$ & $\begin{array}{l}\text { 1. } 7^{\prime \prime} \text { mouth, } \\
\text { eye plus } \\
\text { nose; nose } \\
\text { plus parts of } \\
\text { eye }\end{array}$ & $\begin{array}{l}20^{\prime \prime} \times 5^{\prime \prime} \text { the } \\
\text { face }\end{array}$ & $\begin{array}{l}71 \text { whole } \\
\text { figure }\end{array}$ & \\
\hline far & $12^{\prime}$ & 2. $5^{\prime \prime}$ two eyes & $\begin{array}{l}31^{\prime \prime} \times 7.5^{\prime \prime} \\
\text { faces of } \\
\text { two people }\end{array}$ & $\begin{array}{l}12^{\prime} \text { figure } \\
\text { w/space } \\
\text { around it }\end{array}$ & \\
\hline \multicolumn{6}{|l|}{ Public } \\
\hline & $30^{\prime}$ & $6.3^{\prime \prime}$ the face & $\begin{array}{l}6.3 " \text { torso of } \\
4 \text { or } 5 \text { people }\end{array}$ & $30^{\prime}$ & \\
\hline & $340^{\prime}$ & $6^{1}$ & & & \\
\hline & $500^{\prime}$ & $9^{\prime}$ & & & \\
\hline & $1500^{\prime}$ & $26^{\prime}$ & & & \\
\hline
\end{tabular}

*Computed to nearest 0.1 inch. **:Computed to nearest 0.25 inch. ****Varies with culture.

${ }^{21}$ Hall, "Silent Assumptions in Communication," p. 47. 
non-contact, middle class, educated adults from the eastern seaboard of the United States. The distances Hall describes represent a "first approximation" and "will doubtles seem crude when more is known about proxemic observation and how people distinguish one distance from another. $" 22$ Primarily people in the United States use tactile, visual, and auditory senses. Each distance was discovered to contain a close and far phase. The area between these phases determined the spaces labeled by Hall. Distance refers to a physically measurable distance from one person to another. Space means the distance radiating out from a person on all sides and is determined by the linear distance he maintains with others. The words "space" and "distance" are often used interchangeably in this the sis since they are describing a similar phenomenon.

Social space, different from social distance developed by Borgardus, is usually reserved for social occasions where people desire to keep others at a psychological distance. Usually social distance is used in formal conversations and situations. People working together might use close phase, social distance. ${ }^{23}$ Personal distance indicates that subjects of personal interest or involvement are the most probable topics for discussion. Personal space still allows

\footnotetext{
22 Hall, The Hidden Dimension, p. 109.

23 Ibid., p. 114.
} 
each person his own space bubble. ${ }^{24}$ Entrance into someone's personal space could be considered an insult if one person did not consider the friendship that close. Intimate space is typically reserved for occasions of close, intimate contact. "This is the distance of love-making, wrestling, comforting and protecting. "25 Awareness of the other person is quite heightened. The dimensions of Hall's four spaces are definitively explained in The Hidden Dimension and will not be elaborated any further here except in relation to the hypotheses.

Before considering studies dealing directly with proxemics, the area of pertinent data must be further delineated. Social distance often referred to in social psychology, is different from Hall's category of social distance. Hall is concerned with physical distance, and his term social distance refers to a physically measurable distance.

For the sociologist, social distance refers to a psychological phenomenon which is determined by the culture of a group. "The degree to which individuals are willing to accept people who differ from themselves into their own social group may be considered a 24 Ibid., p. 112.
25 Ibid., p. 110. 
measure of social distance from these out-group persons, $" 26$ The concept was developed by Bogardus who constructed a scale for measuring social distance. Factors which influence social distance are religion, nationality, occupation and sex; and characteristics of the judges--their culture, social class, educational level and personality traits. 27

Many supportive studies have been conducted on social distance. Often the studies are related to attitudes toward different nationalities and ethnic groups. ${ }^{28}$ People within differing cultures appear to share different views about social distance and its determinants. Yet the study of social distance does not account, in any direct way, for physical distance and cultural variations of its use. In the broadest terms people would not probably come in close physical contact with people whom they consider socially distant. The theory of social distance although somewhat related to this study, considers other concepts beyond the field of proxemics. Any future reference to

${ }^{26}$ Harry C. Triandis and Leight H. Triandis, "Some Current Studies in Social Distance, " in Current Studies in Social Psychology, ed. by Ivan D. Steiner and Martin Fishbein (New York: Holt, Rinehart and Winston, Inc., 1965), p. 207.

\section{Ibid. , p. 207.}

${ }^{28}$ Kimball Young, Social Psychology (New York: AppletonCentury-Crofts, 1956), p. 505. 
social distance in this paper refers directly to Hall's concept and not that studied in social psychology.

\section{STUDIES DIRECTLY RELATED TO PROXEMICS}

Physical distance for humans has acquired meaning because of the inhabitants' culture and experience. Osmond coined the terms sociopetal and sociofugal which refer to spatial arrangement people

establish. 29 Sociopetal arrangement of people encourages interaction and sociofugal arrangement discourages interaction and keeps people apart. Sommer, who appears to be one of the few experimenters in the field of spatial relationships, has conducted a few studies utilizing the sociopetal and sociofugal concepts. He studied how people arrange themselves in small discussion groups. The subjects were schizophrenics and non-schizophrenics. Those who were desirous of interaction arranged their chairs in a way that interaction could easily occur. ${ }^{30}$ Sommer also found the larger the room, the closer people sit. ${ }^{31}$ He directly refers to Hall and other

${ }^{29}$ Hall, "Proxemics--A Study of Man's Spatial Relationships," p. 436.

${ }^{30}$ Robert Sommer, "Studies in Personal Space," Sociometry 22 (1959), p. 248.

${ }^{31}$ Robert Sommer, "The Distance of Comfortable Conversation, a Further Study," Sociometry 25 (1962), p. 116. 
sources on which Hall builds his theories. Sommer also notes the lack of research in the field and states, ". . Personal distance is the distance that an organism customarily places between itself and other organisms. . . " and hasn't been studied empirically as yet. 32 Empirical research in proxemics is very limited. In the June 6, 1969 edition of Time, reference was made to some studies being conducted by a psychiatrist, August Kinzel. ${ }^{33}$ Time limitations on the present study did not allow primary source research of the se studies, but the following indicates the apparent nature of Kinzel's work. The study is being conducted at a federal prison in Springfield, Missouri. Kinzel has found that violent and non-violent inmates have different space circles surrounding them. At three feet violent subjects tend to show tension and anxiety when approached by a person, the psychiatrist, for example, in a non-threatening situation. ${ }^{34}$ Nonviolent inmates allow a psychiatrist to approach half that distance before revealing tension. Kinzel also noted the space circle for violent prisoners appears irregular in shape with a bulge in the rear. Kinzel believes the dimensions of the circle may provide some clues to violence potential of its inhabitant. This study supports the

${ }^{32}$ Sommer, "Studies in Personal Space," p. 248.

33 "Violent--The Inner Circle," Time, June 6, 1969, p. 74. ${ }^{34}$ A diagram of the circles of protection appears in Appendix A. 
theories of Hall.

This review has offered more background study than empirical research. Perhaps it would be useful to indicate where the writer has searched for references on this subject. The bibliographical material in Hall's work was utilized first. Footnotes and bibliographies from these sources were also investigated for relevant information, Psychological Abstracts and Sociological Abstracts were also consulted. The librarian indicated that the Sociological Abstracts were usually slow in indexing. Although the tables of contents in current issues were examined, indexing might have led this writer to more references not immediately discernible in the title of the articles. The Reader's Guide and speech journals offered no information. Available issues from the Journal of Communication, which is sometimes not included in indexes, were also examined. The lack of published studies is apparent. This review has revealed that most work in this area has been exploratory, definitive, and analytical. The few empirical and experimentally controlled studies and the authoritative recognition of need for empirical research testify to the infancy of this area of inquiry. The present study will therefore necessarily be broad and explanatory, but experimental in method. 


\section{CHAPTER III}

\section{DESIGN OF THE STUDY}

It is the purpose of this chapter to describe the experimental design. The following areas will facilitate a description: population, experimental variables, content analysis, hypotheses of the study, and procedure.

\section{POPULATION}

The sample was selected from beginning speech classes at Portland State University in the spring of 1969. A list of all students enrolled in beginning speech classes, whose teachers were willing to assist, was compiled. A table of random numbers was used to select 100 potential subjects. These students were invited to participate in an experiment. (See Appendix B.) Those who responded favorably were then scheduled to appear at an appointed time. The total sample of the study numbered 54 people.

When subjects appeared, they were grouped into couples of male-female, male-male, and female-female combinations. There were 27 males and 27 females. Sex was a controlled variable. Subjects were not previously grouped. As the indicated combinations 
became available, they were alternately placed at the three distances until nine couples of the three variations had participated. The population excluded foreign students and racial minority Americans. This variable was considered important because of cultural and subcultural differences that could exist. Speech students were selected because of their availability. The beginning speech classes were utilized to help control the knowledge subjects possessed concerning communication.

\section{EXPERIMENTAL VARIABLES}

The independent variable in this study is spatial distance between people. Three specific distances were examined. These distance variables were intimate, personal, and social distance as described by Hall. He describes a close and far phase for each distance which encompasses the space of that distance. For instance, social distance in its closest phase (phase being Hall's term) is 4 feet and in its farthest phase 12 feet. The distances used in this experiment represent the half way point between the closest and farthest phase. Therefore intimate distance was set at 9 inches between the noses of the two participants, personal distance was set at 3 feet 9 inches, and social distance was established at 8 feet. These measurements approximate the spaces described by Hall. All subjects were asked to remain seated in order to control vertical' 
distance. For example, conversants in an intimate distance space situation could differ in height. Their eyes would not meet horizontally. A shorter subject looking up to a taller subject might produce different responses than if subjects were facing one another directly.

\section{CONTENT ANALYSIS}

Berelson defines content analysis as "a technique for the objective, systematic and quantitative description of the manifest content of communication. " 1 This research technique focuses on the message aspect of a communicative act. ${ }^{2}$ The use of content analysis is based on three assumptions: a relationship exists between intent and content; manifest content is meaningful; and, quantitative description of communication content is meaningful. ${ }^{3}$ Accepting the se assertions, inferences can be made cautiously. The two main processes involved in content analysis are determining content characteristics and applying rules for identifying and recording those

${ }^{1}$ Bernard Berelson, Content Analysis in Communication Research (Glencoe: The Free Press, 1952), p. 15.

${ }^{2}$ Richard W. Budd, Robert K. Thorp, and Donohew Lewis, Content Analysis of Communications (New York: Macmillan Company, 1967), p. 2.
${ }^{3}$ Berelson, Content Analysis in Communication Research, p. 21 . 
characteristics. 4

In communication, several processes are active. The categories were constructed on the hypothesis that certain reactions, thoughts, and feelings of the subjects would be manifested in specific ways. Since this experiment was a contrived situation, some reference to the situation was to be expected in the content of the conversation. People react psychologically to a setting. Accordingly, categories were constructed to describe the psychological state of the subjects as revealed by a series of questions about the data: How much did subjects refer to the speaking situation? Were subjects apparently tense or uncomfortable? Once subjects were conversing, did they become involved in the conversation and reveal attitudes to one another? Did subjects choose to talk about themselves or others? These kinds of questions led to the creation of eight categories: references to the speaking situation, time orientation of the conversation, references to self and others, amount of pause time, tension releases, kinds of statements, vocal reinforcements and changing the topic of conversation. Below is an explanation of the categories and specifications which were used in each analysis.

${ }^{4}$ Philip Stone, Dexter C. Dumphy, Marshall S. Smith, and Daniel Ogilvie, The General Inquirer: A Computer Approach to Content Analysis (Cambridge: MIT Press, 1966), p. 7. 
$\underline{\text { Reference to the Speaking Situation }}$

Each sentence that included a reference to the situation, the laboratory in which the study was conducted, the tape recorder or those who would be listening to the tape, was counted.

\section{Time Orientation}

Time orientation refers to verb tenses used. The verbs indicate whether sentences were constructed in the past, present, or future tense. Each verb was counted even in short parenthetical segments of a sentence such as "you know," and "I mean." Sentences using "should," "would," or "could," were considered based on the meaning inherent within the entire sentence. For example, if a person were referring to a situation which "could" or. "would" occur, the verbs within this sentence or clause were considered future oriented since it was not presently occurring to the speaker. Subjunctive clauses were considered in the same manner.

\section{References to Self and Others}

All first person pronouns (plural, singular, or possessive) were counted as references to self. All third person pronouns (singular or plural), collective nouns, proper and common nouns which refer to people, and relative pronouns referring to people were counted as references to others. Nouns that could be used as references to people, but in the sentence referred to a role (predicate 
nominatives for example) were not counted. An example would be: "She is a teacher." "She" would be counted, but "teacher" would not. Such a statement as: "The teacher was ill, "would be tabulated as one reference to other because "the teacher" refers to a person. Any nouns or pronouns which indicate an amount of people, was not counted. An example would be: "one of them." "One" would not be counted, but "them" would be counted.

\section{$\underline{\text { Pause Time }}$}

Total pause time was determined by the use of a stop watch. A pause was recorded on the stop watch each time it occurred. The total pause time was measured for the five minutes' length of each tape on three different occasions and then averaged in order to minimize measuring errors.

\section{Tension Releases}

Laughing, coughing, sighing, and gasping were considered tension releases. As the tapes were transcribed these vocalizations were placed in parentheses where they occurred in order to facilitate counting during the analysis. Each time a laugh occurred it was placed within the transcript and counted individually. It would be possible then for several tension releases to occur within a sentence. 
$\underline{\text { Kinds of Statements }}$

This dimension utilized certain of Bales "interaction analysis" categories. ${ }^{5}$ The statements were first divided into two categories of "asking" and "giving information"--one categorization Bales makes. The "giving information" was then subdivided into "suggestion, "opinion," and "factual-type information." Suggestions included statements which indicate a course of action to be taken. An opinion was considered as a reported attitude or value statement. Some statements were difficult to classify as to opinion or fact, and then the following procedure was used: If inference was used by the speaker to come to his conclusions, this was considered an opinion because personal values and definitions helped to establish the statement. An example would be, "The elementary school teacher is using poor teaching methods, "which indicates a value judgment and thus an opinion. Informative statements of a factual nature included public and private fact. An example would be: "Portland State is a campus school," (public fact) or "I don't like him, " (private fact). 6

${ }^{5}$ Robert F. Bales, Interaction Analysis Process Analysis (Cambridge: Addison-Wesley Press, 1950), p. 9.

${ }^{6}$ Knowledge of Rokeach's belief system was used in this discrimination. Milton Rokeach, Beliefs, Attitudes and Values (San Francisco: Jossey, Bass Inc., 1968). 
Changing the Subject

Each time a new general topic of conversation was introduced, a change of subject was recorded. If subjects talked about academic work and then employment outside school a change would be counted. A shift in focus of the conversation served as one clue and broken continuity as another. Changes were counted only when the whole topic moved to another general area of concern.

\section{Vocal Reinforcements}

Short, one or two word interjections (not followed by a statement which would be classified in types of statements) were counted as vocal reinforcement. The interjections could show approval or disapproval or simply be vocalizations with no meaning except to act as feedback and acknowledgment that one person was listening to the other. The word "no" was generally counted as an answer to a question, thus giving information and not simply an interjection. Examples of vocal reinforcement would be "yeh," "really," and "uh huh."

These categories were hypothesized to be social adaptation indices of conversants. The categories are not exhaustive but are representative of various elements in a communicative act--the source, message, symbolic system, receiver, feedback, and setting. To establish reliability some transcripts were analyzed twice to as certain whether a tabulation would repeat itself, which it did. Also 
when unanticipated problems arose the first time, more explicit specifications were developed. The characteristic indices became tighter in their description to increase reliability to a satisfactory degree.

\section{HYPOTHESES OF THE STUDY}

The general hypothesis in this study is that verbal content of interpersonal communication will vary as distance changes. Specific hypotheses are proposed in relation to the categories of content analysis. Eight specific hypotheses are stated below to indicate what is expected and why. From these hypotheses and their explanations, some rationale is outlined for inferences which may be drawn.

Hypothesis 1. Frequency of reference to the speaking situation will vary with the distance variables.

Since proximity suggests specific types of interpersonal contact, references to the situation are expected most often in intimate distance conversations. Intimate distance is usually reserved for intimate situations. It allows and encourages "involvement with another body. $" 7$ If one person is very close to another, visual focus is lost. "The nose is over-large and may look distorted, as well as

${ }^{7}$ Hall, The Hidden Dimension, p. 110. 
other features such as the lips, teeth, and tongue. ${ }^{8}$ Since subjects are "strangers," it seems predictable they would refer most often to the unusual situation. Even personal space is usually invaded only by those people we know. Yet this personal space is more penetrable by strangers than is intimate distance. Therefore, fewer references to the speaking situation are expected in the personal distance.

Social distance, on the other hand, is usually maintained between strangers. There is little reason to anticipate many references to the situation in the social distance conversations. Since the subjects were aware of the tape recorder's presence and the strange situation, it is possible that all will react in the same manner, but it is anticipated that some conditions will produce more references than others.

Hypothesis 2. Time orientation as revealed by verb tense will vary with the distance variable.

Mehrabian and Weiner develop the concept of "immediacy." It is defined as "the relationship between the speaker and the objects he communicates about, the addressee of his communication, or the ${ }^{8}$ Ibid. , p. 111 . 
communication itself. 19 Several variations in immediacy are presented by them. They hold that language communicates how clearly a person wishes to be aligned with a situation. One category is temporal relations which are most often expressed through verb tense. ${ }^{10}$ It is then suggested that certain variations in language (verb tense) are". . often used explicitly to designate (the) degree of separation of a communicator from the objects of his communication. "11 Normal conversation utilizes past, present, and future time orientations. If people feel personally involved in a situation, this attitude could be revealed by speaking more in the present tense than in the past or future tense. It is expected that conversants within intimate space will feel more involved by their proximity to each other. Heavier use of present tense verbs is expected than in personal or social distance conversations. Declining use of the present tense is anticipated in personal distance; even fewer references are expected at social distance.

Hypothesis 3. Frequency of references to self and others will vary with the distance variables.

${ }^{9}$ Morton Wiener and Albert Mehrabian, Language Within Language: A Channel in Verbal Communication (New York: Appleton-Century-Crofts, 1968), p. 3.
$10_{\text {Ibid., p. } 35 .}$
$11_{\text {Ibid. , p. } 36 .}$ 
Immediacy can be manifest also through the use of pronouns. 12 Variations in pronoun usage can indicate where a person places himself in a situation and where he places others. ${ }^{13}$ How many times subjects refer to self and others is expected to reveal immediacy to that situation. The desire to escape a situation is likely to produce fewer references to self and more to people and objects distant from the communicants. Therefore, since subjects in intimate distance are hypothesized to be uncomfortable, fewer references to the self are anticipated than in personal distance. Personal distance would include more self references and the most self references would be employed in social distance.

Hypothesis 4. Total pause time will vary with the distance variables.

Experience in social interaction places certain expectations on behavior. When people are in a situation in which they are expected to communicate verbally, they feel they should do just that--communicate. The more aware people are of this purpose, the less likely they are to allow pauses. Silence produces discomfort in an on-going conversation. Within intimate distance the subjects' main visual field is limited to each other. Their awareness is heightened by the close proximity of another person's physical presence. It
12 Ibid., p. 29.
13 Ibid. 
seems likely these subjects would be more aware of each other than of the room. As stated previously intimate distance forces a person's attention on the physical facial features of another. At personal distance visual distortion doesn't occur to such a great extent as it does at intimate distance. ${ }^{14}$ Another person's body is visible above the waist. Background features become visible. ${ }^{15}$ The chances for physical contact are lessened. At social distance "nobody touches or expects to touch another. 16 There is no forced attention on another person's face. Generally there are fewer reasons to feel uncomfortable in the personal and social distance. Likewise people in social distance can sense visually, not only the other person, but many other environmental stimuli as well. For these reasons less total pause time is expected in intimate distance. More pause time is predicted to exist for those in personal distance. The greatest pause time is expected within social distance conversations when the silence is not perceived as uncomfortable or as long.

Hypothesis 5. Signs of tension will vary with the distance variables.

${ }^{14}$ Hall, The Hidden Dimension, p. 112.

${ }^{15}$ See Appendix B which offers a photograph of a person at all three distances and how he is seen by the viewer.

${ }^{16}$ Hall, The Hidden Dimension, p. 114. 
Different types of vocal behavior often reveal tension, such as laughing, throat clearing, and sighing. The intimate distance, as explained earlier, is likely to be perceived as the most awkward. More tension releases are expected at this distance. Decreasing amounts of tension are expected in personal and social distance, and, consequently, fewer signs are expected.

Hypothesis 6. Types of statements will vary with the distance variables.

Sentences can be classified in two general categories. Declarative statements give information and interrogative statements ask for information. "Giving information" will be sub-divided into three areas: giving suggestion, giving opinion, and giving non-opinion. People usually allow only those they trust into intimate and personal proximity. Therefore through previous experience it seems predictable that more statements of opinion and suggestions will be stimulated. The physical distance encourages more involvement by the use of such statements. Social distance is likely to keep subjects more formal and less close psychologically. If it is discovered that more opinions and suggestions are given in social distance, then such an outcome might be explained in terms of psychological safety. Social distance would not appear to commit the communicators to each other as much. This distance does not indicate affection or 
close association. The threat of rejection is less because there is not as much concern with alienating a person for whom one has no feeling. Therefore, people may feel freer to express value statements or opinions, thus altering the types of information given.

Hypothesis 7. Frequency in changing the topic of conversation will vary with the distance variables,

No specific predictions are made in this category because of the various possibilities that seem equally possible. People change a topic of conversation for various reasons. One reason may be nervousness. Another reason could be simply exhaustion of a topic. Also perhaps one person's statement might suggest another topic to the other and to which he immediately responds. If changing the topic is an indication of nervousness, the most changes would be expected in intimate distance. However, since intimate distance primarily encourages involvement, it seems most likely this situation will lead to a more in-depth conversation on a topic. This hypothesis i must serve a descriptive function rather than a predictive one.

Hypothesis 8. The frequency of short vocal reinforcements is expected to differ between intimate, personal, and social distances. 
These reinforcements, not carrying any specific information, are likely to reveal involvement subjects feel in the conversation. Marsh and Barna found tense subjects used more reinforcements than assumed relaxed subjects. ${ }^{17}$ It is expected that the subjects, although uncornfortable, will become involved with each other when they are in intimate and personal distance. Therefore, people probably feel obligated to offer more feedback responses in order to substantiate their interest in another's ideas. Social distance is typically more formal in nature, There is likely to be less enthusiasm in the conversation.

\section{PROCEDURE}

The procedure followed in this study included several steps which are outlined below.

1. Students chosen by random sampling were invited to participate in an experiment. (See Appendix C.) Those willing were informed of the date and time the experiment was to begin.

2. Upon arrival of subjects, they were placed in pairs, No two people who knew each other were placed together.

3. Subjects were separated into three groups of nine couples

${ }^{17}$ Patrick O. Marsh and LaRay Barna, "An Empirical Study of the Effects of Systematic Relaxation Training upon Selected Variables as Manifested in Recorded Spontaneous Diadic Conversation, " A Report to the Portland State College Research and Publications Committee, 1967. (Mimeographed.) 
each. The couples consisted of three male-male pairs, three female-female pairs, and three male-female pairs for each distance.

4. Each couple then participated in a ten-minute conversation which was tape recorded. They were placed in a 10 foot by 17 foot room with no windows. Nine pairs conversed at each of the three distances. Instructions were read to each couple. (See Appendix D.) Precautions were taken to check the distance subjects kept during the interview.

5. Five minutes from each tape was transcribed. The first two minutes were disregarded as were the last three minutes. This five-minute segment was felt to represent best the total conversation and not to include immediate awkwardnesses or final dwindling in conversations.

6. The content analysis was conducted according to the explanations previously outlined.

7. The several hypotheses were treated in the traditional null form in the statistical analyses. The chi-square and $\underline{t}$ tests were performed, where appropriate, in the usual manner to furnish the statistical interpretations of the data. 


\section{CHAPTER IV}

\section{FINDINGS}

The purpose of this chapter is to present the findings of the study. Each of the eight hypotheses will be presented along with the statistical interpretation. ${ }^{1}$ Chapter $\mathrm{V}$ will summarize and interpret what the findings seem to suggest.

Seven categories were analyzed by the chi-square test and one category, pause time, utilized the $\underline{t}$ test in its interpretation. All were one-tail tests of the null hypothesis. Tables will be given for each hypothesis presenting the observations, expectations and final results of the chi-square tests or $\underline{t}$ test.

Hypothesis 1. Frequency of reference to the speaking situation will vary with the distance variables.

The null hypothesis was rejected in the "references to the speaking situation" category. A very significant-difference was revealed $(p<.01)$. At two degrees of freedom the .01 level required

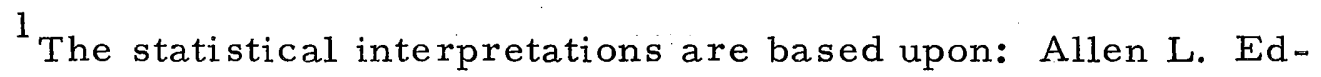
wards, Experimental Design in Psychological Research (New York: Rinehart and Company, Inc., 1956). Since all chi-square tests are based upon more than one degree of freedom, correction for continuity is not required (p. 100). 
for significance is 9.210. The chi-square was considerably higher at 18.326. Subjects situated at the three distances did differ from each other in their verbal reference to the speaking situation. Table II, below, indicates the basis for these findings.

TABLE II

CHI-SQUARE TEST FOR THE VARIABLE "REFERENCES TO THE SPEAKING SITUATION"

\begin{tabular}{lccc}
\hline \hline Distance & Observations & Expectations & $\frac{(\mathrm{o}-\mathrm{e})^{2}}{\mathrm{e}}$ \\
\hline Intimate & 1 & 8.33 & 6.449 \\
Personal & 6 & 8.33 & .652 \\
Social & 18 & 8.33 & 11.225 \\
\hline Total & 25 & & $18.326 * *$ \\
\hline
\end{tabular}

Note: For all tables in this chapter, significance will be indicated in the following manner: (*) significant at the . 05 level; (**) significant at the .01 level.

Hypothesis 2. Time orientation as revealed by verb tense will vary with the distance variables.

Time orientation as revealed by verb tense differed between the three distance variables at a very significant level with a chi-square of 30.642. To be significant at the .01 level, 13.277 is necessary. The null hypothesis was rejected thus indicating the samples do not 
statistically appear to have been uncontrolled. Below, Tables III, IV, and V present the statistical data.

TABLE III

TIME ORIENTATION REVEALED BY VERB TENSE

(OBSER VED FREQUENCY)

\begin{tabular}{lcccc}
\hline \hline Distance & Past & Present & Future & Total \\
\hline Intimate & 257 & 685 & 149 & 1091 \\
Personal & 293 & 751 & 135 & 1179 \\
Social & 336 & 698 & 87 & 1121 \\
\hline Total & 886 & 2134 & 371 & 3391 \\
\hline \hline
\end{tabular}

TABLE IV

TIME ORIENTATION REVEALED BY VERB TENSE (EXPECTED FREQUENCY)

\begin{tabular}{lccc}
\hline \hline Distance & Past & Present & Future \\
\hline Intimate & 284.969 & 686.566 & 119.355 \\
Personal & 307.954 & 741.945 & 128.983 \\
Social & 292.805 & 705.445 & 122.637 \\
\hline
\end{tabular}


TABLE V

CHI-SQUARE TEST FOR TIME ORIENTATION

REVEALED BY VERB TENSE

\begin{tabular}{lcccc}
\hline & \multicolumn{3}{c}{$(\mathrm{o}-\mathrm{e})^{2} / \mathrm{e}$} \\
\cline { 2 - 5 } Distance & Past & Present & Future & Total \\
\hline Intimate & 2.745 & .004 & 7.363 & 10.112 \\
Personal & .726 & .190 & 2.807 & 3.723 \\
Social & 6.372 & .079 & 10.356 & 16.807 \\
\hline Total & 9.843 & .273 & 20.526 & 30.642 *** \\
\hline \hline
\end{tabular}

An analysis of the components of Table $\mathrm{V}$ yields more information about the sources of difference reported there. At the intimate distance, an extremely significant difference $\left(\chi^{2}=444.60\right)$ was deter mined between frequency of tenses used. Present tense had the highest frequency, future tense the next, and past tense the last. At the personal distance a similar relationship was revealed $\left(x^{2}=455.99\right)$. But at the social distance a reversal of order was discovered; while the present tense was used most frequently, the past tense was used next and the future tense least $\left(\chi^{2}=225.639\right)$. Table VI illustrates these various ordinal effects.

The same data analyzed by tense-grouping rather than by distance-grouping produced a chi-square of $10.607(\mathrm{p}<.01)$ for the past tense. In other words, the hypothesis that the three distances 
TABLE VI

HIERARCHY OF VERB-TENSE PREFERENCES

ACCORDING TO DISTANCE GROUP

\begin{tabular}{clll}
\hline & & Distance & \\
\cline { 2 - 4 } Rank Order & Intimate & Personal & Social \\
\hline 2 & Present & Present & Present \\
3 & Future & Future & Past \\
\hline
\end{tabular}

use the past tense with equal frequency must be rejected. The intimate and social distances showed marked deviations from expectancy. For the present tense, however, a non-significant chi-square was found $\left(x^{2}=3.438\right)$. The hypothesis of equal frequency of usage at different distances (except for chance deviations) must be accepted. A very significant difference between distance groups was $\varsigma$ found for frequency of future tense usages $\left(X^{2}=16.056\right)$. Again the intimate and social distances account for the deviation from expectancy.

Hypothesis 3. Frequency of references to self and others will vary with the distance variables.

The null hypothesis was accepted in this category. The chisquare score of 4.699 fell short of the necessary 5.991 to be 
significant at the .05 level. This result seems to indicate that controlled distance did not affect subjects' references to self and others. Tables VII, VIII, and IX, below, present the findings.

TABLE VII

REFERENCES TO SELF AND OTHERS

(OBSER VED FREQUENCY)

\begin{tabular}{lccc}
\hline \hline Distance & Self & Others & Total \\
\hline Intimate & 449 & 598 & 1047 \\
Personal & 570 & 701 & 1271 \\
Social & 373 & 544 & 917 \\
\hline Total & 1392 & 1843 & 3235 \\
\hline
\end{tabular}

TABLE VIII

REFERENCES TO SELF AND OTHERS

(EXPECTED FREQUENCY)

\begin{tabular}{lcc}
\hline Distance & Self & Others \\
\hline Intimate & 450.41 & 587.26 \\
Personal & 546.78 & 712.90 \\
Social & 394.49 & 514.34 \\
\hline
\end{tabular}


TABLE IX

CHI-SQUARE TEST FOR REFERENCES TO SELF AND OTHERS

\begin{tabular}{lccc}
\hline Distance & Self & Others & Total \\
\hline Intimate & .439 & .196 & .635 \\
Personal & .986 & .198 & 1.184 \\
Social & 1.170 & 1.710 & 2.880 \\
\hline Total & 2.595 & 2.104 & 4.699 \\
\hline
\end{tabular}

Hypothesis 4. Total pause time will vary with the distance variables.

The $\underline{t}$ test was used in this statistical interpretation, and it revealed no significant differences. Three tests were run comparing intimate and personal distance, intimate and social distance, and personal and social distance. Although there was no significant difference in any of the three tests, it is interesting to note that intimate and personal distance and personal and social distance were very similar in their results being. 7501 and .7533 respectively. The intimate and social distance $\underline{t}$ score was .2189. Table X represents a summary of data used in the $\underline{t}$ test. 
TABLE X

SUMMARY OF t-TEST RESULTS FOR PAUSE TIME

\begin{tabular}{lccccc}
\hline \multicolumn{1}{c}{ Comparison } & $\mathrm{N}$ & d. f. & $\mathrm{m}_{1}-\mathrm{m}_{2}$ & $\mathrm{~S}_{\mathrm{x}_{1}-\overline{\mathrm{x}}_{2}}$ & $\underline{\mathrm{t}}$ \\
\hline Intimate-Personal & 9 & 16 & 11.34 & 15.118 & .7501 \\
Intimate-Social & 9 & 16 & 3.44 & 15.710 & .2189 \\
Personal-Social & 9 & 16 & 7.90 & 10.488 & .7532 \\
\hline
\end{tabular}

Hypothesis 5. Signs of tension will vary with the distance variables.

Tension releases were very significantly different between the three distances. Subjects did reveal varying signs of tension in in timate, personal and social distances. The null hypothesis was rejected. The information leading to these results appears in Table XI.

TABLE XI

CHI-SQUARE TEST FOR SIGNS OF TENSION

\begin{tabular}{lccc}
\hline & Observations & Expectations & $\frac{(0-\mathrm{e})^{2}}{\mathrm{e}}$ \\
\hline Distance & 93 & 71 & 6.816 \\
Personal & 56 & 71 & 3.169 \\
Social & 64 & 71 & .690 \\
\hline Total & 213 & & $10.675 * *$ \\
\hline \hline
\end{tabular}


Hypothesis 6. Types of statements will vary with the distance variables.

This category analyzed first the difference between "asking" and "giving" information. There was a very significant difference $(\mathrm{p}<.01)$ thus rejecting the null hypothesis. "Giving information" was then subdivided into statements of "opinion," "factual-type information," and "suggestion." Here no significant difference was found. The null hypothesis was accepted in this subdivision of "asking" for information. Below, Tables XII, XIII, XIV, XV, XVI, and XVII show the basis for these findings.

The results of the chi-square test for "asking" and "giving" information were subjected to further analysis. For each distance a highly significant difference was found between "asking" and "giving" information. When the three distances were compared to each other, intimate distance conversants asked and gave the highest amount of information, social distance ranked second in "asking" and "giving," and personal distance had the least amount of both "asking" and "giving." 
TABLE XII

"ASKING" AND "GIVING" INFORMATION

(OBSERVED FREQUENCY)

\begin{tabular}{lccc}
\hline \hline Distance & "Asks" & "Gives" & Total \\
\hline Intimate & 151 & 677 & 828 \\
Personal & 76 & 582 & 658 \\
Social & 137 & 645 & 782 \\
\hline Total & 364 & 1904 & 2268 \\
\hline
\end{tabular}

TABLE XIII

"ASKING" AND "GIVING" INFORMATION

(EXPECTED FREQUENCY)

\begin{tabular}{lcc}
\hline Distance & "Asks" & "Gives" \\
\hline Intimate & 132.81 & 695.10 \\
Personal & 105.54 & 552.39 \\
Social & 125.43 & 656.48 \\
\hline
\end{tabular}


TABLE XIV

CHI-SQUARE TEST FOR "ASKING" AND "GIVING" INFORMATION

\begin{tabular}{lccc}
\hline \hline Distance & "Asks" & "Gives" & Total \\
\hline Intimate & 2.491 & .471 & 2.962 \\
Personal & 8.268 & 1.587 & 9.855 \\
Social & 1.067 & .200 & 1.267 \\
\hline Total & 11.826 & 2.258 & $14.084 * *$ \\
\hline
\end{tabular}

TABLE XV

"GIVING" INFORMATION - -OPINION, FACTUAL INF ORMATION, SUGGESTION (OBSERVED FREQUENCY)

\begin{tabular}{lcccc}
\hline \hline Distance & Opinion & Information & Suggestion & Total \\
\hline Intimate & 153 & 519 & 5 & 677 \\
Personal & 161 & 462 & 6 & 629 \\
Social & 191 & 549 & 8 & 748 \\
\hline Total & 505 & 1530 & 19 & 2054 \\
\hline \hline
\end{tabular}


TABLE XVI

"GIVING" INFORMATION--OPINION, FACTUAL INFORMATION, SUGGESTION

(EXPECTED FREQUENCY)

\begin{tabular}{lccc}
\hline \hline Distance & Opinion & Information & Suggestion \\
\hline Intimate & 166.40 & 504.22 & 6.22 \\
Personal & 154.60 & 468.47 & 5.78 \\
Social & 183.85 & 557.11 & 6.88 \\
\hline \hline
\end{tabular}

TABLE XVII

CHI-SQUARE TEST FOR "GIVING INFORMATION"-OPINION, FACTUAL INFORMATION, SUGGESTION

\begin{tabular}{lcccc}
\hline Distance & Opinion & Information & Suggestion & Total \\
\hline Intimate & 1.079 & .433 & .237 & 1.749 \\
Personal & .264 & .893 & .837 & 1.994 \\
Social & .278 & 1.180 & .181 & 1.639 \\
\hline Total & 1.621 & 2.506 & 1.255 & 5.382 \\
\hline \hline
\end{tabular}

Hypothesis 7. Frequency in changing the topic of conversation will vary with the distance variables.

The null hypothesis was rejected in this category. A significant difference was found $(p<.05)$. Changing the topic of 
conversation did vary when subjects were placed at the three controlled distances. The results and their bases appear below in Table XVIII. Conversation topics changed most frequently at the intimate distance, next at the social distance, and least at the personal distance. The intimate distance dyads changed topics twice as frequently as the personal group. Intimate and personal dyads were very similar in number of changes.

TABLE XVIII

CHI-SQUARE TEST FOR CHANGE IN THE TOPIC OF CONVERSATION

\begin{tabular}{lccc}
\hline \hline Distance & Observations & Expectations & $\frac{(\mathrm{o}-\mathrm{e})^{2}}{\mathrm{e}}$ \\
\hline Intimate & 36 & 25.67 & 3.390 \\
Personal & 18 & 25.67 & 2.291 \\
Social & 33 & 25.67 & 2.092 \\
\hline Total & 87 & & $7.773 *$ \\
\hline
\end{tabular}

Hypothesis 8. Frequency of short vocal reinforcements will vary with the distance variables.

The frequency of vocal reinforcements did indeed differ. At the .01 level the chi-square required for significance is 9.210 . The score was 40.901 which is a very significant difference. The null 
hypothesis was rejected. Table XIX appears below and offers the statistical analysis of the findings. The personal distance accounted for the greatest deviation; that group made significantly fewer rein forcements than the other groups.

TABLE XIX

CHI-SQUARE TEST FOR FREQUENCY

OF VOCAL REINF ORCEMENTS

\begin{tabular}{lccc}
\hline \hline Distance & Observations & Expectations & $\frac{(\mathrm{o}-\mathrm{e})^{2}}{\mathrm{e}}$ \\
\hline Intimate & 136 & 114.33 & 4.107 \\
Personal & 73 & 114.33 & 33.410 \\
Social & 134 & 114.33 & 3.384 \\
\hline Total & 343 & & $40.901 * *$ \\
\hline \hline
\end{tabular}

There were a total of nine statistical tests employed to analyze the eight categories. A significant difference at the .05 level was found in one category, and at the .01 level in five categories. Of all the nine tests, then, six were found to significantly differ between the distance variables and two categories revealed no significant differences. These totals do not include statistical interpretations which grew out of the originally planned categories to be analyzed. Significant differences were found in frequency of references to the speaking situation, time orientation as revealed by verb tense, signs of 
tension, types of statements, frequency of changing the topic of conversation, and frequency of short vocal reinforcements. 


\section{CHAPTER V}

\section{SUMMARY AND CONCLUSIONS}

This final chapter will summarize and interpret the information produced by the findings. The several hypotheses will be stated once again with the relevant results. Inferences will then be drawn about behavior which was exhibited in the three distance variables. Suggestions for further research will conclude this chapter.

\section{SUMMARY OF THE FINDINGS}

Hypothesis 1. Frequency of reference to the speaking situation will vary with the distance variables.

1. There was a very significant difference between the three distances with intimate and social distance deviating most from the expected frequency. Intimate distance subjects avoided mentioning the situation almost completely, and subjects in social distance referred to it quite frequently.

2. Personal distance approximated most closely what would be expected in an uncontrolled situation.

Hypothesis 2. Time orientation as revealed by verb tense will vary with the distance variables. 
1. A very significant difference was found in the verb tense that subjects chose to use at the varying distances.

2. All subjects chose to use the present tense most frequently.

3. Intimate and personal distance subjects preferred the future tense as their second time orientation and utilized past tense least often in comparison to the present and future tenses.

4. Subjects in social distance utilized the past tense as second preference to present and the future tense least often.

Hypothesis 3. Frequency of references to self and others will vary with the distance variables.

1. There were no significant differences in the use of references to self and others in the conversations representative of intimate, personal and social distance. The purpose of this category was to also reveal "immediacy" to the situation. The original hypothesis stated that the more subjects wish to avoid the situation, the less references to self would be employed, thus reducing the immediacy to the situation and indicating a desire to escape.

2. Two possible reasons are suggested as to why no significance was found. Perhaps the category did not adequately specify the references. The grouping of "references to 
self" and "references to others" may have been too generalized to yield significant differences. The other hypotheses dealing with avoidance of the situation and immediacy are supported indicating that subjects were aware of the distance variable. Another reason might be that "references to self and others" will simply not indicate subjects' psychological state. It is most strongly felt, however, that the category is useful but needs refinement.

Hypothesis 4. Total pause time will vary with the distance variables.

1. No significant difference existed in this category.

2. However, intimate and personal distance and personal and social distance were quite similar in their deviation from the expected frequency. A trend suggested that intimate and social distance deviation might be different from the other two combinations in replicative studies. Perhaps this indicates that intimate and social distance are more alike than when compared with personal distance.

3. It is believed that no significance was found because subjects' rate of speaking differed. This suggestion is supported by the data offered in the "asking" and "giving" information category. All conversations were analyzed for a five-minute time span, and yet the amount of information 
passed between subjects differed markedly. It seems pos sible that the distance variable affected subjects' speaking rate and consequently the total pause time balanced with the total amount of verbal activity.

Hypothesis 5. Signs of tension will vary with the distance variables.

1. Tension releases were significantly different among the three distances.

2. The raw data reveal intimate distance conversants used more tension releases, social used less, and personal distance used the least amount.

3. Social distance can be observed to deviate least from the expected frequency and intimate distance deviates the most.

Hypothesis 6. Types of statements will vary with the distance variables.

1. There was a significant difference in the "asking" and "giving" of information and no significant differences in the three sub-categories of "giving" information (opinion, factual information, suggestion).

2. Intimate distance conversations had the highest amount of "asking" and "giving" information. Social distance was second in both cases and personal distance subjects asked 
and gave the least amount of information. These findings lead us to hypothesize that the speaking rates differed allowing for more or less information to pass between conversants.

3. The reason for no significant findings in the sub-category of opinion, factual information, and suggestion may be explained as follows. It was originally hypothesized that psychological security at social distance would allow for freer exchange of opinion and suggestion. It has been discovered that personal distance was the most comfortable for subjects, thus changing this expectation. Still no differences were found. An inherent problem with this kind of analysis is validity; while precautions were taken to insure analysis validity, this remains a possible explanation. Intent may not be analyzable according to verbal content in this subjective category, especially differentiating between fact and opinion.

Hypothesis 7. Frequency in changing the topic of conversation will vary with the distance variables.

1. The groups differed significantly in changing the topic of conversation. 
2. Intimate distance conversants deviated most from the expected frequency.

Hypothesis 8 . The frequency of short vocal reinforcements will vary with the distance variables.

1. Short vocal reinforcements differed at a highly significant level.

2. Intimate and social distances used the most amount of total reinforcements and were almost identical to each other.

3. Personal distance deviated most from the expected frequency, and subjects in this distance used the least amount of vocal reinforcements.

\section{CONCLUSIONS}

The results of this study have produced some highly significant findings. Only two categories, "references to self and others" and pause time did not reject the null hypothesis. The sub-category, types of "giving" information, also accepted the null hypothesis although the general category, "kinds of statements, "did reveal a significant difference. The general hypothesis that the verbal content of interpersonal communication will vary as distance changes appears to be strongly supported. The specific information provided by the eight detailed hypotheses can lead to some cautious 
generalizations about how subjects react when placed in a setting which controls their distance from one another.

\section{Intimate Distance}

Intimate distance, set at nine inches in this study, was hypothesized to be the most uncomfortable for subjects who were not acquainted. The subject did reveal several signs of nervousness.

Tension releases were more frequent than in any other distance. The topic of conversation was also changed more often than it did in the other distances. There was a high amount of vocal reinforcement which could be attributed to uneasiness. Intimate distance contained the highest amount of "asking" and "giving" information, possibly indicating a faster rate of speaking and fear of silence. As proposed earlier, subjects may have been so aware of each other, that even the shortest pauses were perceived as long, thus keeping the conversation very alive with verbal activity. A desire to escape the immediate situation was also apparent. Practically no references to the speaking situation were made; and when not speaking in the present, subjects spoke of the future.

People appear to associate intimate distance with intimate situations. Circumstances which do not coincide with our expectations about spatial distance appear to produce atypical verbal behaviors. These verbal signs serve to indicate the psychological state of 
individuals in a communicative situation. What people say carries subconscious indications of how they feel. Very close proximity between two unacquainted people has an effect on their communication.

\section{Personal Distance}

Personal distance of three feet, nine inches in this study was believed also to be uncomfortable for subjects but less than intimate distance. This generalization was based on Hall's general statements about personal distance, a distance reserved for those we know and wish to communicate with on a personal level. Insofar as we assume that strangers are not likely to want to communicate on a personal level, this study rejects the expectations of the writer. Personal distance appears to have been the most comfortable dis tance for conversation. There were not an unusual number of references to the speaking situation. The smallest frequency of tension releases, vocal reinforcements, and topic changes were made at this distance. The lowest amount of "asking" and "giving" information appeared within personal distance. The low degree of changing the topic of conversation seems to indicate that a topic was dealt with more thoroughly. The lowest amount of "asking" occurred at this distance perhaps implying that subjects did not need prodding to keep their conversation moving.

One might normally expect two people who meet in order to 
become acquainted would probably situate themselves at a personal distance. Their main purpose is to become personally involved with one another. This seems the likely reason why subjects at the personal distance were the most comfortable. Placed in a situation which encouraged verbal interaction, subjects behaved in the most natural fashion and set out to become acquainted. They were not overly aware of the situation because each person was the primary focus of the other's visual field. Proximity probably helped to recall previous experiences of a personally-involving situation, and subjects behaved in this way, calm and apparently not highly threatened.

\section{Social Distance}

Social distance, originally proposed to be the most comfortable, was revealed to be second to intimate distance in total signs of subjects' awareness of the distance variable. Subjects spoke most frequently in this distance of the situation itself. When not using the present tense, they chose to refer to the past, perhaps indicating a choice to avoid the present. Nervousness was revealed by the second highest amount of tension releases and a high degree of vocal reinforcements. The topic of conversation changed almost as frequently as it did in intimate distance situations. Subjects appeared generally to feel less uncomfortable than those in intimate distance but more aware of their situation than personal distance subjects. 
Social distance is usually kept between non-talking strangers or those involved in formal situations. This distance is not comfortable for people who are trying to sustain a conversation and become acquainted. Sitting eight feet from another person does not duplicate other situations in which people become personally involved and feel at ease with another person. Social distance might also allow for more awareness of surroundings and a constant reminder of the circumstances under which the conversation is occurring.

In summary it can be said that subjects feel most at ease in personal distance when they are conversing continually in an effort to become acquainted. People in social distance are less comfortable when talking continuously with another person. Intimate distance is threatening and extremely uncomfortable for total strangers.

\section{SUGGESTIONS FOR FURTHER RESEARCH}

Since significant differences have been revealed in this study, there are several areas of further research that suggest themselves. The first related variable was the subjects chosen. People from another culture, according to Hall, have different spatial behavior. Therefore subjects representative of another culture might have different verbal behavior in relating to varying spatial distances. Sex could also be manipulated to see if differences occur between all male, all female, or all male-female groups. Even people who are 
not strangers may reveal differences although it seems likely that the null hypotheses would be accepted.

In this study the far and near phase of each distance was not studied but the mid-point between the two. Perhaps these dimensions would be worth consideration. Vertical distance was also controlled and might prove to be an important variable.

Each of the categories which revealed significance at the .01 level could easily be developed into an area of specialized study. What is the role of vocal reinforcement to communication in varying distances? What leads people to change the topic of conversation? The descending order of "giving" and "asking" for information as an index to subjects' psychological state appears worth analysis. Does the rate of speaking differ between the distances? Time orientation in avoidance situations is another area for study. Certainly other categories could be constructed and used in analyzing the same data or could be added if the study were replicated.

Some general questions related to proxemics have also grown from the study. How do people naturally situate themselves when desirous of becoming acquainted with another person? Does the size of the room affect how people naturally group themselves?. What are the frequencies of spatial distance used by people during an average day? Do they spend more time in personal, social, or intimate distance? If strangers remain in a certain spatial relationship to one 
another for a determined length of time, does their behavior begin to approximate behavior usually associated with that distance?

All of these questions support what was stated earlier that the study of proxemics is still in its infancy. Many questions remain unanswered, thus defining specific areas of future research. The value of studies in proxemics is in uncovering its effect on communication and its importance in the understanding of human behavior. 


\section{REF ERENCES}

Bales, Robert F. Interaction Process Analysis. Cambridge: Addison-Wesley Press, 1950.

Beals, Ralph L. , and Hoijer, Harry. An Introduction to Anthropology. New York: The Macmillan Company, 1965.

Berelson, Bernard. Content Analysis in Communication Research. Glencoe: The Free Press, 1952.

Budd, Richard W., Thorp, Robert K., and Donohew, Lewis. Content Analysis of Communications. New York: Macmillan Company, 1967.

Carpenter, C. R. "Territoriality: A Review of Concepts and Problems." Behavior and Evolution. Edited by A. Roe and G. G. Simpson. New Haven: Yale University Press, 1958.

Edwards, Allen L. Experimental Design in Psychological Research. New York: Rinehart and Company, Inc., 1956.

Hall, Edward T. "Proxemics--A Study of Man's Spatial Relationships." Man's Image in Medicine and Anthropology. Edited by I. Gladston. New York: International Universities Press, 1.963.

Hall, Edward T. "Silent Assumptions in Social Communication." Disorders in Communication, XLII. Edited by. Rioch and Weinstein. Baltimore: Williams and Wilkins Company, 1964.

Ha1l, Edward T. The Hidden Dimension. Garden City: Doubleday and Company, Inc., 1966.

Hall, Edward T. The Silent Language. Garden City: Doubleday and Company, 1959.

Howard, Ian P. Human Spatial Orientation. New York: Wiley, 1966.

LeBarre, Weston. The Human Animal. Chicago: University of Chicago Press, 1954. 
Marsh, Patrick O., and Barna, LaRay. "An Empirical Study of the Effects of Systematic Relaxation Training upon Selected Speech Variables as Manifested in Recorded Spontaneous Diadic Conversations." A Report to the Portland State College Research and Publications Committee, 1967. (Mimeographed.)

Rokeach, Milton. Beliefs, Attitudes and Values. San Francisco: Jossey, Bass, Inc., 1968.

Sebeok, T. "The Evolution of Signaling Behavior." Behavioral Science 7, 430-442.

Sommer, Robert. "Studies in Personal Space." Sociometry, 22 (1959), 247-260.

Sommer, Robert. "The Distance of Comfortable Conversation, A Further Study." Sociometry, 25 (1952), $111-116$.

Sorokin, Pitirim A. Sociocultural Causality, Space, Time: A Study of Referential Principles of Sociology and Social Science. New York: Russell and Russell, 1964.

Steinzor, B. "The Spatial Factor in Face-to-Face Discussion Groups." Small Groups. Edited by P. Hare, E. Borgatta, and R. F. Bales. New York: Knopf, 1955.

Stone, Philip J., Dunphy, Dexter C., Smith, Marshall S., and Ogilvie, Daniel. The General Inquirer: A Computer Approach to Content Analysis. Cambridge: The MIT Press, 1.966.

Triandis, Harry C., and Triandis, Leigh H. "Some Studies in Social Distance." Current Studies in Social Psychology. Edited by Ivan D. Steiner and Martin Fishbein. New York: Holt, Rinehart and Winston, Inc., 1965.

VonUexkull, F. M. "A Stroll through the Worlds of Animals and Men." Instinctive Behavior. Edited by C. Schiller. New York: International Universities Press, 1957.

"Violence--The Inner Circle." Time. June 6, 1969. 79.

Weiner, Morton, and Mehrabian, Albert. Language Within Language. New York: Appleton-Century-Crofts, 1968.

Young, Kimball. Social Psychology. New York: Appleton-CenturyCrofts, 1956. 


\section{APPENDICES}


APPENDIX A

KINZEL'S THEORY OF THE VIOLENT AND NONVIOLENT MAN

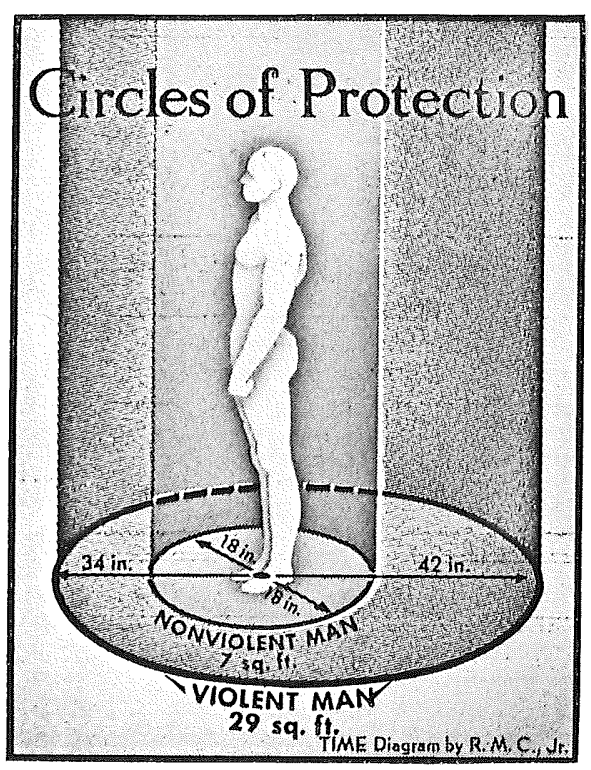

"Violence--The Inner Circle," Time, June 6, 1969, 74. 


\section{APPENDIX B}

\section{VISUAL FIELD OF A PERSON AT INTIMATE, PERSONAL, AND SOCIAL DISTANCE}

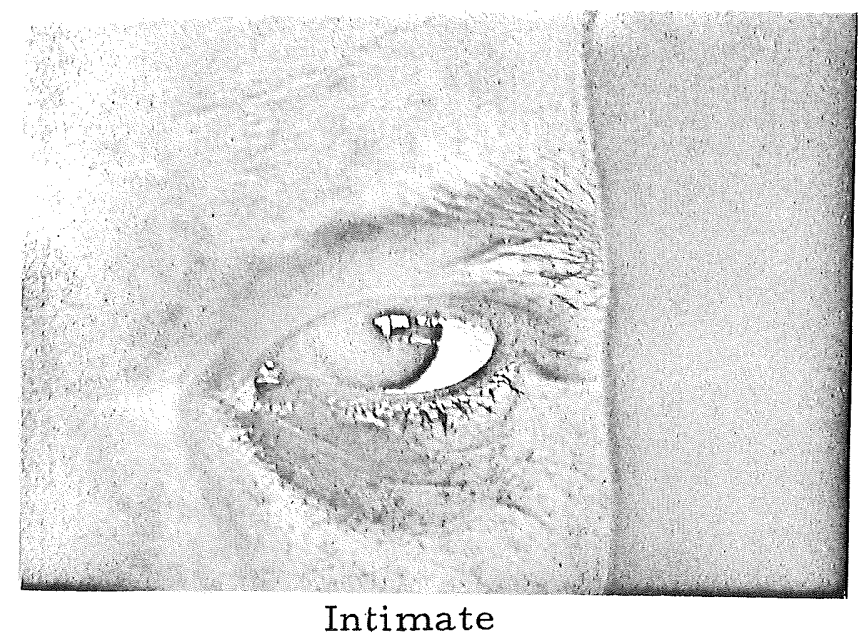

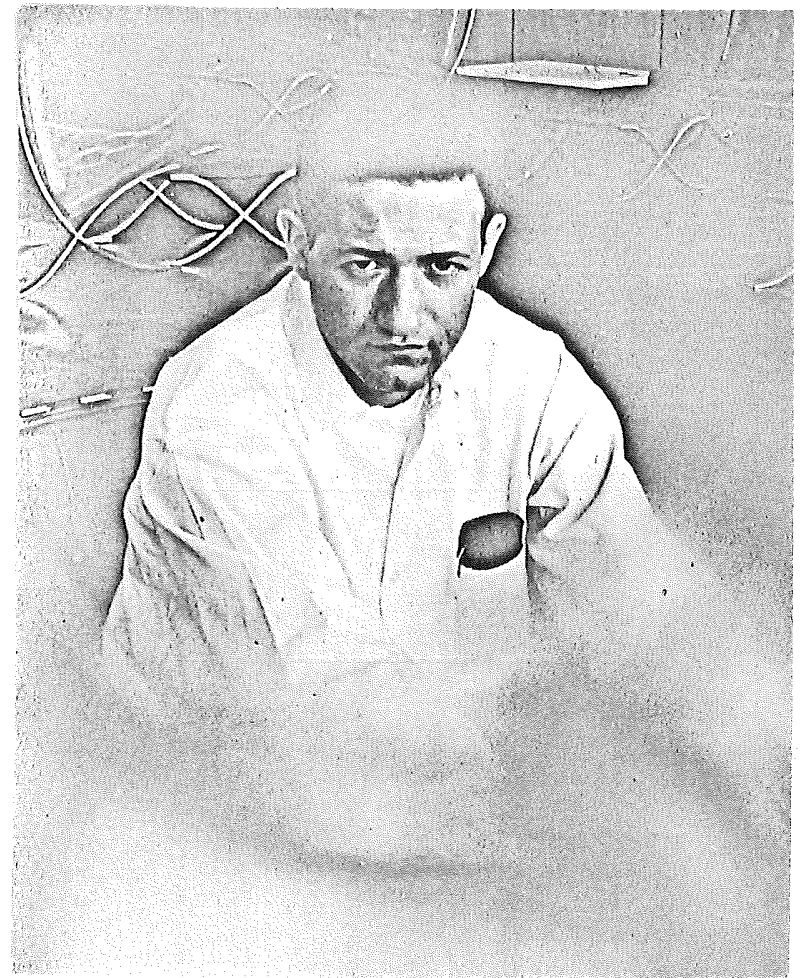

Personal

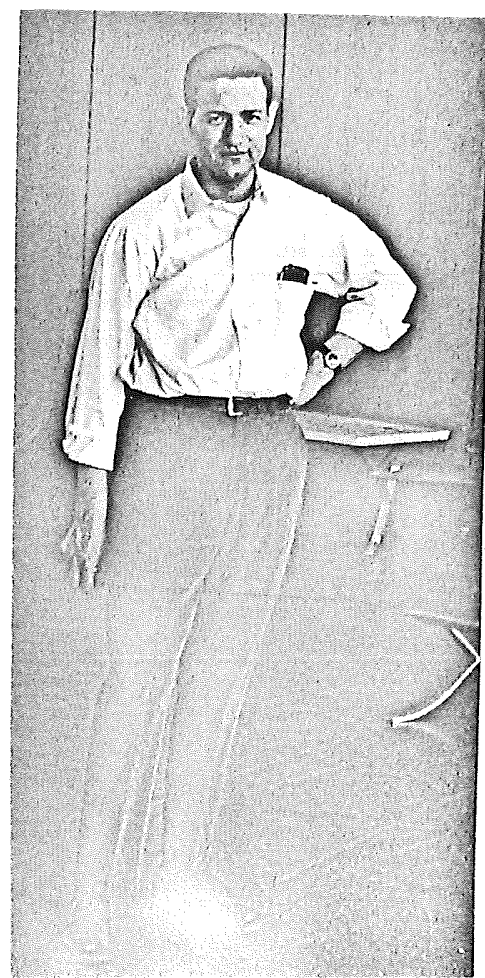

Social

Hall, The Hidden Dimension, Plates 10, $11,12$. 


\section{APPENDIX C}

\section{INVITATION ASKING STUDENT PARTICIPATION}

\section{Dear}

Through a scientific process of sample selection which is designed to insure representativeness, you have been selected to participate in a communication experiment. It is important in order to maintain proper experimental control to have you participate if it is at all possible. Less than an hour of your time will be required. The study concerns "proxemics" (effects of distance in communication). You will find the participation interesting, and if you participate, the results of the study will be available to you. In order to maintain experimental control, further details on the purpose of the study must be suppressed until all subjects have been selected.

Check the following times that would be convenient for you to participate. Do not mark a time during your speech class. Please return this to your instructor.

$$
\begin{array}{ll}
M, W, F, \quad \begin{array}{ll}
10: 00 \\
11: 00
\end{array} & \text { T, Th 2:00 } \\
2: 00 & \text { Can't Participate }
\end{array}
$$




\section{APPENDIX D}

\section{INSTRUCTIONS READ TO SUBJECTS BEFORE THEIR CONVERSATION WAS TAPED}

The purpose of this experiment is to study the effects of spatial differences on communication. You are requested to converse with each other for the next ten minutes. This conversation will be taped. I will leave the room when the tape begins and will return in ten minutes. Do not move your chairs at all but leave them in this present position. Do not stand up or move about the room but remain seated. When the experiment is over, you are free to leave the lounge area. Please do not discuss this procedure with other prospective subjects. For scientific reasons all subjects need to have equal knowledge about what is occurring. In about three weeks you will receive a letter of explanation about this study and its hypothesis as well as your role in the study. Thank you for participating.

Do you have any questions before we begin? 